\title{
Skin Cancer of the Face in Albinos: Case Management
}

\author{
Amady Coulibaly ${ }^{1,2^{*}}$, Sibiri Traoré1, Sory Ibrahima Sidibé1, Koniba Diabaté2,3, Youssouf Sidibé2,4, \\ Garango A. Allaye1, Mariam G. Diallo1, Abdramane S. Maiga5, Boubacar Ba ${ }^{1,2}$, Hamady Traoré1,2, \\ Alhousseyni Ag Mohamed ${ }^{2}$
}

\author{
${ }^{1}$ Department of Stomatology and Maxillofacial Surgery, CHU-CNOS, Bamako, Mali \\ ${ }^{2}$ Faculty of Medicine and Odontostomatology, Bamako, Mali \\ ${ }^{3}$ Radiotherapy Department of the Hospital of Mali, Bamako, Mali \\ ${ }^{4}$ Departement of Otorhinolaryngology, CHU Mère-Enfant "le Luxembourg", Bamako, Mali \\ ${ }^{5}$ Military Hospital of Bamako, Bamako, Mali \\ Email: *coulibalyamady@yahoo.fr
}

How to cite this paper: Coulibaly, A. Traoré, S., Sidibé, S.I., Diabaté, K., Sidibé, Y., Allaye, G.A., Diallo, M.G., Maiga, A.S., Ba, B., Traoré, H. and Mohamed, A.A. (2022) Skin Cancer of the Face in Albinos: Case Management. International Journal of Otolaryngology and Head \& Neck Surgery, 11, 31-38.

https://doi.org/10.4236/ijohns.2022.111005

Received: October 15, 2021

Accepted: December 15, 2021

Published: January 25, 2022

Copyright $\odot 2022$ by author(s) and Scientific Research Publishing Inc. This work is licensed under the Creative Commons Attribution-NonCommercial International License (CC BY-NC 4.0). http://creativecommons.org/licenses/by-nc/4.0/ (c) (i) \&) Open Access

\begin{abstract}
Albinism represents a set of genetic abnormalities characterized by a decrease or absence of melanin. Albinism in the black subject combines white skin and other morphological characteristics of the black race. Squamous cell carcinomas of the face in albinos are a common reason for consultation. Management remains most often complex. The objective of this work was to describe the management of a case of skin cancer of the face in an albino woman. She was a 26-year-old albino woman. She is a housewife and married. She consulted on 02/04/17 for a tumor of the right side. The tumour was about $6 \mathrm{~cm}$ in diameter and had been growing for 7 months. There was no palpable head and neck disease. The rest of the clinical examination was normal. The biopsy concluded that there was squamous cell carcinoma. The extension assessment had not found a secondary location. She received an excision of the tumor with a margin of $10 \mathrm{~mm}$ and a total skin graft. The trend has been favourable after three years. No recurrence was observed. The management of facial skin cancer should be the subject of a multidisciplinary consultation. Surgery occupies an important place in the therapeutic arsenal.
\end{abstract}

\section{Keywords}

Skin Cancer, Face, Albino, Treatment

\section{Introduction}

Albinism represents a set of genetic abnormalities characterized by a decrease or 
absence of melanin. It is associated with a normal number and structure of melanocytes. It is a hereditary condition that is transmitted in an autosomal recessive manner [1]. Prevalence is variable and is estimated to range from $1 / 17,000$ to $1 / 20,000$ people in North America and Europe. Prevalence can wait for 1/1000 people in selected populations. In Africa, the prevalence estimate is $1 / 000$ people for some specific groups. The most characteristic manifestation of albinism is hypopigmentation of the skin, hair, hair and eyes. Albinism in the black subject combines white skin and other morphological characteristics of the black race [2] [3] [4]. Cutaneous squamous cell carcinoma or squamous cell carcinoma is a group of malignant epithelial tumors primary skin cells that express squamous differentiation and are distinct from basal cell carcinomas. Squamous cell carcinomas of the face in albinos are a common reason for consultation. Management remains most often complex. Surgical excision is the standard treatment if we haven't a pejorative clinical criterion [3] [4].

The objective of this work was to describe the management of a case of skin cancer of the face in an albino woman.

\section{Observation}

She was a 26-year-old albino woman. She is a housewife and married. She consulted on 02/04/17 for a tumor of the right side. The tumour was about $6 \mathrm{~cm}$ in diameter and had been growing for 7 months. The patient has no particular medical-surgical history. She is non-alcoholic, however, there was the notion of prolonged exposure to the sun for household chores and field work.

On clinical examination, the general condition was preserved with a WHO grade 1 index. The extraoral examination found facial asymmetry related to an ulcerative-budding swelling located on the right hemiface with an indurated base, pedicled "cauliflower" appearance measuring $6 \mathrm{~cm}$ long (Figure 1).

The swelling was painful on palpation, bleeding on contact. There was no

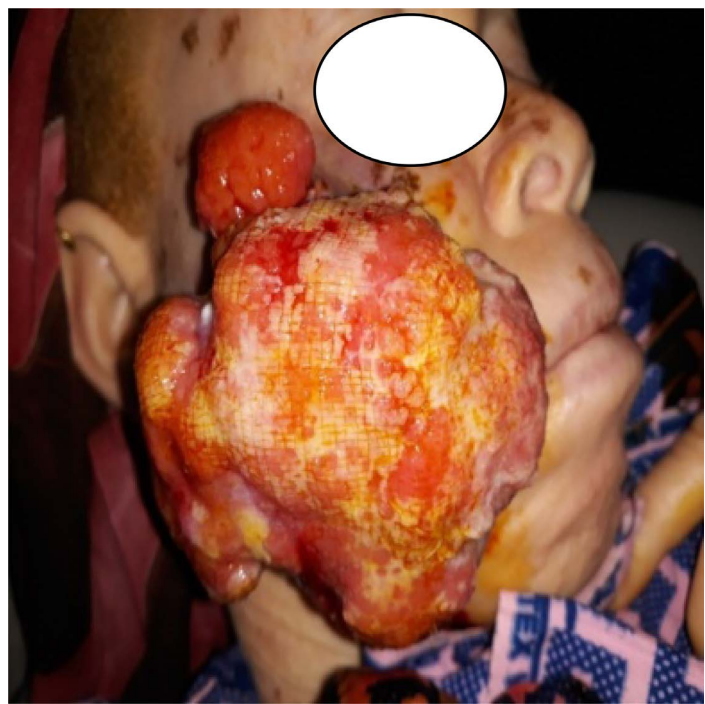

Figure 1. Appearance of the tumor before surgery. 
palpable head and neck lymphadenopathy. The remainder of the physical examination was unremarkable. The maxillofacial computed tomography (CT) scan did not show any bone lysis or lymphadenopathy (Figure 2).

A biopsy was performed after operability workup and the result was in favor of moderately differentiated squamous cell carcinoma (Figure 3). There was a tumor proliferation made up of lobules. Tumor cells are polygonal, with an atypical, large, irregular nucleus. The latter is surrounded by an abundant eosinophilic cytoplasm with clear cytoplasmic boundaries in a clear frame. Signs of dyskeratotic maturation are noted in the form of horny globes. The stroma is inflammatory and fibrous.

The extension workup performed, in particular thoraco-abdominal CT and cervical ultrasound, did not find any secondary location. Thus, the diagnosis of

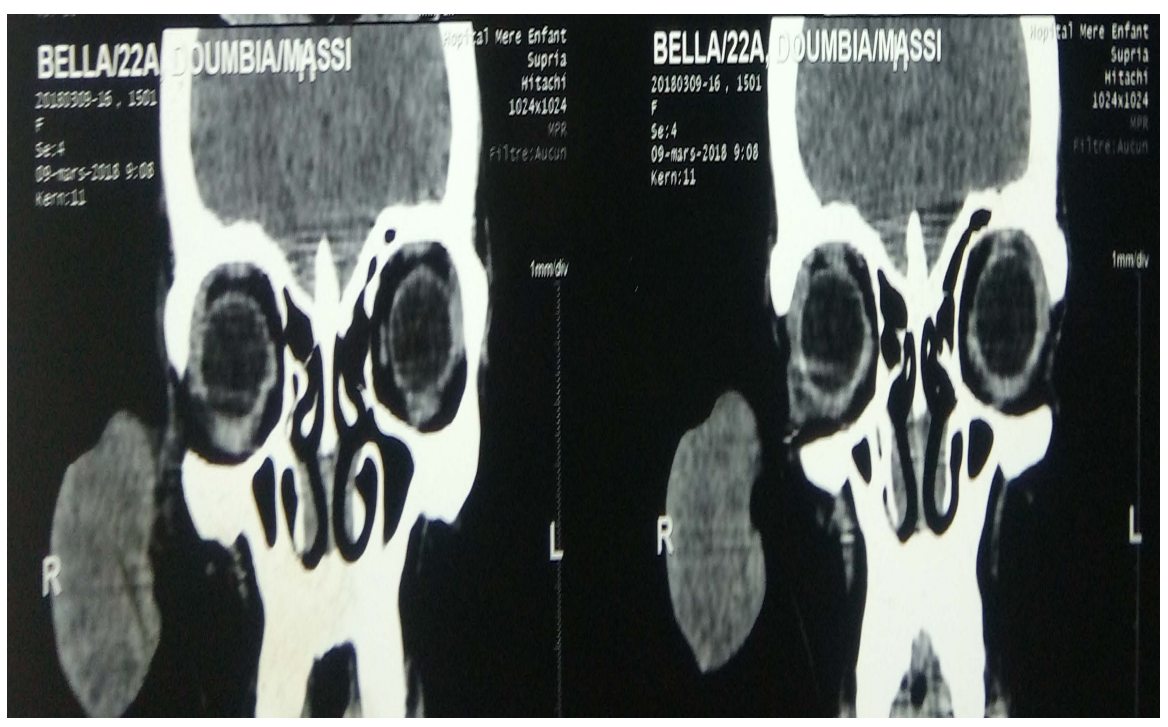

Figure 2. CT appearance showing the tumor process without underlying bone involvement.

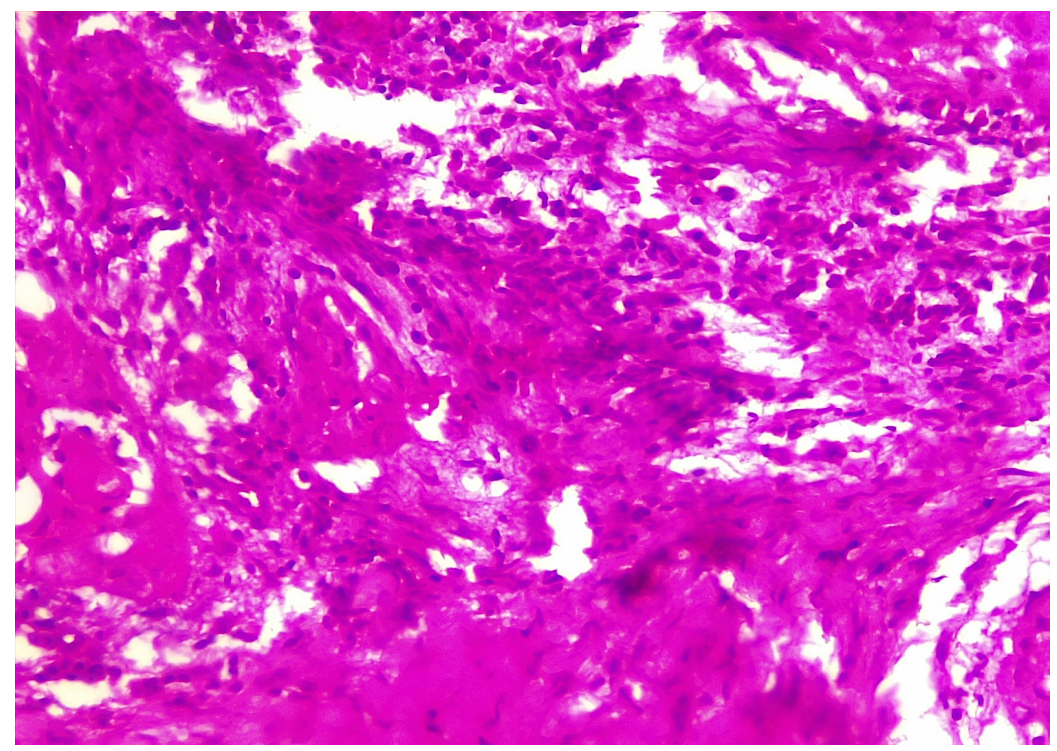

Figure 3. Histological appearance. 
cutaneous squamous cell carcinoma (classified as T3N0M0 was retained. After discussion in a multidisciplinary consultation meeting, the patient first benefited from an excision with a resection margin of $10 \mathrm{~mm}$ from the tumor border associated with ipsilateral functional lymph node dissection under general anesthesia with orotracheal intubation (Figure 4).

The result of the pathological examination confirmed a histologically complete resection. A month later, a total skin graft taken from the inner side of the left thigh was performed to cover the loss of substance (Figure 5).

Complete healing occurred 2 weeks later (Figure 6). The patient did not

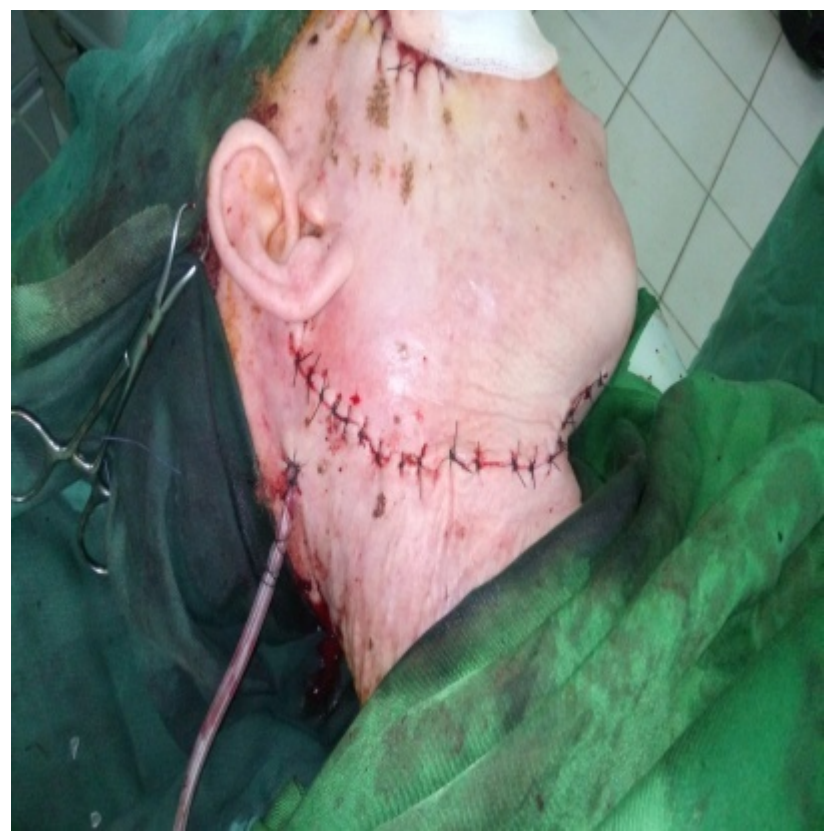

Figure 4. Aspect at the end of the operation.

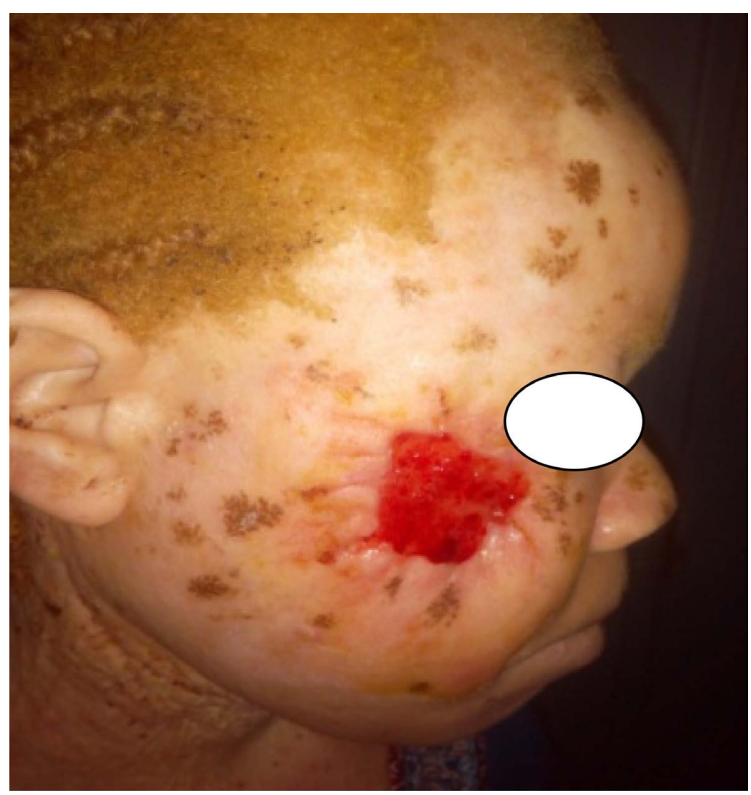

Figure 5. Patient on D10 postoperative. 


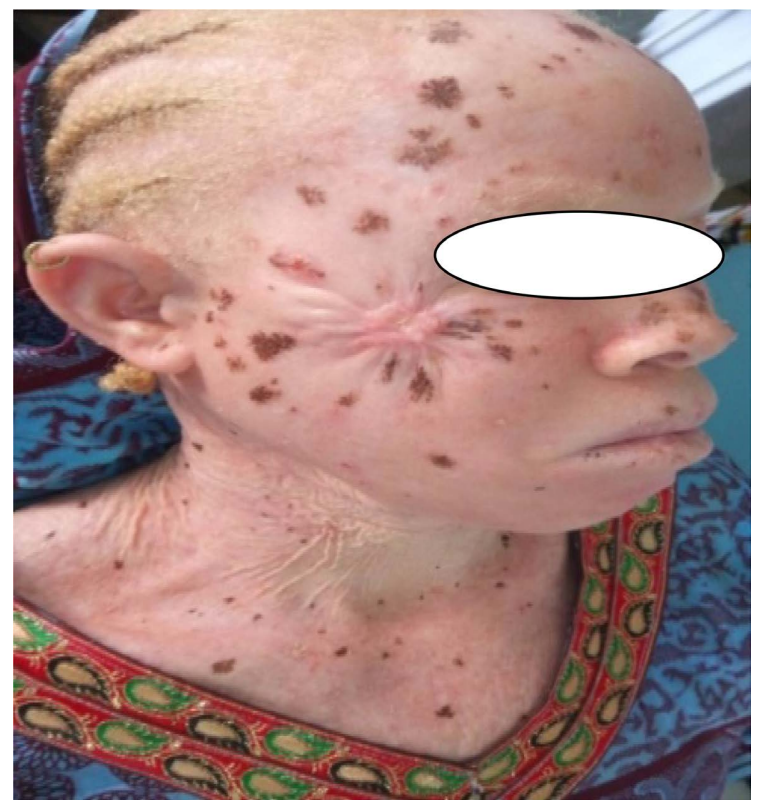

Figure 6. Appearance 6 months after surgery.

receive radiation therapy and chemotherapy. The evolution was favorable, there was no recurrence after a three-year follow-up.

\section{Discussion}

Squamous cell carcinomas are relatively frequent and are more aggressive in the general population with a high risk of secondary dissemination [2] [4] [5] [6]. Young subjects are the most affected [2] [3]. The predominance of these cancers is reported in populations with black skin [3] [4] [7] [8] [9]. The localization at the level of the head and the neck constitutes a reason for relatively frequent consultation. Some authors [3] have reported 56 cases over a 12-year period. The main locations were as follows: forehead: 20 cases (35\%), scalp: 11 cases (19.6\%), temporal area: 8 cases (14.2\%), cheek: 6 cases (10.7\%) [3]. Skin carcinomas have a considerable economic impact due to the treatments they cause (ablative and cosmetic surgery, radiotherapy, cryotherapy). In Australia, where the incidence is the highest in the world, skin carcinoma is the most expensive cancer. In the United States, it represents the fifth cancer in terms of costs with expenditure estimated at 562 million dollars annually, 20 times more than for melanoma. The costs related to hospitalizations alone are between 105 and 130 million euros per year for skin carcinomas in Germany, against 50 to 60 million euros for the melanoma. These figures underestimate the real costs since they exclude outpatient treatment, which accounts for the majority of situations, as well as the indirect costs linked to morbidity, lost productivity and premature death [10] [11] [12]. These injuries most often occur in a context of very unfavorable socio-economic precariousness for this category of people. Insufficient financial resources, lack of education and information, stigma and discrimination, are all deleterious factors that affect the quality of life of albinos [4]. In the reported case, the med- 
ical assistance scheme provided financial support. The duration of development of the tumor is variable. For some authors [3], it was 16 months on average. It was associated with inflammatory lymphadenopathy in 22 cases $(39.2 \%)$, and with bone involvement in 10 cases (17.5\%). In the reported case, the tumor had been growing for 7 months and there was no localization of the lymph node. Ultraviolet (UV) rays emitted by the sun are known to be responsible for most squamous cell carcinomas (50\% to $70 \%$ ) and basal cells (50\% to $90 \%$ ). Although the mechanisms by which repeated UV exposure leads to the appearance of skin neoplasms are not still fully elucidated, the individual behavior facing the sun is the determining factor for the UV dose received. Individual risk is strongly modulated by personal characteristics (phenotype, genetic predisposition, history of skin cancer) and individuals with fair hair and skin are particularly at risk. Based on epidemiological studies, it has been shown that the relationship between the UV dose received and the risk of carcinoma differs between squamous and basal cell types. Chronic type exposure appears to be predominant in the induction of squamous cell carcinoma for which the risk increases with the total dose received [10] [13]. Excessive exposure during childhood, especially with severe sunburn, appears to be increase the risk of carcinoma. While exposure to ultraviolet radiation is the main causative factor, the etiology of skin carcinomas is multifactorial. It remains, in many respects, unexplained, which may seem paradoxical for such a frequent cancer. Ionizing radiation, polycyclic hydrocarbons (tar, carbon, paraffin), arsenic, which may seem paradoxical for such frequent cancer. Ionizing radiations, polycyclic hydrocarbons (tar, charcoal, paraffin), arsenic, pesticides, certain industrial solvents, dyes and oils, as well as chronic immunosuppression (especially in transplant recipients) are among the other established risk factors. Certain skin conditions and genetic syndromes such as chronic ulceration, burn scars, albinism or Xeroderma pigmentosum have been associated with an increased risk of skin cancer, especially squamous cell carcinoma. Pesticides, some industrial solvents, tinctures and oils, and chronic immunosuppression (especially in transplant recipients) are other established risk factors [10] [14]. In our reported case, there was the notion of prolonged exposure to the sun.

The management must be the subject of multidisciplinary consultation in order to choose the best strategy for the patient [15]. In our case, the meeting brought together surgeons, oncologist, radiotherapist, dermatologist and anesthesitis. Surgery is the treatment of choice for squamous cell carcinoma. It has the advantage of providing a piece of excision allowing histological confirmation of the diagnosis and verification of the quality of the excision, and obtaining a very high rate of local control and the cure of a large majority of patients. Surgical treatment must meet certain objectives: be curative, functional and aesthetic [15]. In the reported case, surgery was proposed, the safety margin was observed and the excision was histologically complete. The excision must be carcinological, that is to say, complete from the outset, to limit the risk of locoregion- 
al and distant recurrence [15] [16]. Complementary treatment can be offered for tumors ineligible for surgery, which was not the case in the patient. Radiotherapy should in no case be a substitute for first-line surgery and EC are considered to be not very chemosensitive. While the prognosis is generally good in small tumors, it remains poor for metastatic forms, despite treatment, the overall 5 -year survival rate does not exceed 34\% [15] [16]. In our reported case, the patient did not receive radiotherapy or chemotherapy.

\section{Conclusion}

The management of skin cancer of the face in albinos must be the subject of multidisciplinary consultation regardless of the stage. Surgery has a preponderant place in the therapeutic arsenal. A complete surgical excision will cure most of the cases. Regular monitoring, photo-protection of clothing and the use of sunscreen cream can prevent these cancers in albinos.

\section{Conflicts of Interest}

The authors declare no conflicts of interest regarding the publication of this paper.

\section{References}

[1] Aquaron, R. (2000) L'albinisme humain: Aspects cliniques, genetiques, cellulaires, biochimiques et moleculaires. Médecine Tropicale, 60, 331-341.

[2] Rooryck, C., Morice, F., Mortemousque, B., et al. (2007) Albinisme oculo-cutané, Annales de Dermatologie et de Vénéréologie, 134, 55-64. https://doi.org/10.1016/S0151-9638(07)89250-7

[3] Gbery, I.P., Kouame, K., Kouassi, K.A., et al. (2016) Les tumeurs cutanées céphaliques chez les albinos à Abidjan. Annales de Dermatologie et de Vénéréologie, 143, S29. https://doi.org/10.1016/S0151-9638(16)30154-5

[4] Kakiese, V.M., Iteke, M., Nkwembe, R.M., et al. (2016) Lésions cutanées observées dans l'albinisme occulo-cutané: Résultats d'une campagne de dépistage dans la ville-province de kinshasa. Annals of African Medicine, 9, 2395-2399.

[5] Okulicz, J.F., Shah, R.S., Schwartz, R.A. and Janniger, C.K. (2003) Oculocutaneous albinism. Journal of the European Academy of Dermatology and Venereology, 17, 251-256. https://doi.org/10.1046/j.1468-3083.2003.00767.x

[6] Jannot, A.S., Meziani, R., Bertrand, G., et al. (2005) Allele Variations in the OCA2 Gene (Pink-Eyed-Dilutionlocus) Are Associated with Genetic Susceptibility to Melanoma. European Journal of Human Genetics, 13, 913-920. https://doi.org/10.1038/sj.ejhg.5201415

[7] Saka, B., Souley, Z. and Kombate, K. (2010) Les cancers cutanés au Togo: 223 observations. Med Trop, 70, 169-171.

[8] Kapayi, A.K. (2017) Cancer cutané du visage chez les albinos: Souvent une impasse thérapeutique dans notre pratique chirurgicale. Annals of African Medicine, 11, $2-5$.

[9] Traore, B., Keita, M., Conde, M., et al. (2016) Caractéristiques anatomo-cliniques des cancers cutanés à l'unité de chirurgie oncologique du CHU de Conakry. Revue du CAMES, 4, 78-81. 
[10] Bulliard, J.L., Panizzon, R.G. and Levi, F. (2009) Epidemiologie des cancers epitheliaux de la peau. Revue Médicale Suisse, 5, 882-888.

[11] Karagas, M.R., Weinstock, M. and Nelson, H.H. (2006) Keratinocyte Carcinomas (Basal and Squamous Cell Carcinomas of the Skin). In: Schottenfield, D. and Fraumeni, J.F., Eds., Cancer Epidemiology and Prevention, Oxford University Press, New York, 1230-1250. https://doi.org/10.1093/acprof:oso/9780195149616.003.0064

[12] Australian Institute of Health and Welfare (2005) Health System Expenditures on Cancer and Other Neoplasms in Australia, 2000-01. AIHW, Canberra, 68 p.

[13] Housman, T.S., Feldman, S.R., Williford, P.M., et al. (2003) Skin Cancer Is among the Most Costly of All Cancers to Treat for the Medicare Population. Journal of the American Academy of Dermatology, 48, 425-429.

https://doi.org/10.1067/mjd.2003.186

[14] Diepgen, T.L. and Mahler, V. (2002) The Epidemiology of Skin Cancer. British Journal of Dermatology, 146, 1-6. https://doi.org/10.1046/j.1365-2133.146.s61.2.X

[15] El Kettani, M.A. (2017) Tumeurs cutanées malignes de la face: Prise en charge diagnostique et thérapeutique à propos de 48 cas. Thèse de médecine $\mathrm{N}^{\circ} 085$, Faculté de médecine de Marrakech, 73-130.

[16] Degardin, N., Delesalle, F., Mortier, L., et al. (2009) Chirurgie des tumeurs cutanées. Elsevier Masson SAS, Issy-les-Moulineaux. 